\title{
Chemical Composition and Antioxidant Activities of Five Samples of Prunus mume Umezu from Different Factories in South and East China
}

\author{
Zhi-Yi Chen, Yao-Sheng Lin, Xue-Ming Liu, Jing-Rong Cheng, and Chun-Ying Yang \\ Sericultural \& Agri-Food Research Institute, Guangdong Academy of Agricultural Sciences, Key Laboratory of Functional Foods, \\ Ministry of Agriculture, Guangdong Key Laboratory of Agricultural Products Processing, Guangzhou 510610, China \\ Correspondence should be addressed to Xue-Ming Liu; xuemingliu@21cn.com
}

Received 6 August 2017; Accepted 3 December 2017; Published 19 December 2017

Academic Editor: Alberto Fiore

Copyright (c) 2017 Zhi-Yi Chen et al. This is an open access article distributed under the Creative Commons Attribution License, which permits unrestricted use, distribution, and reproduction in any medium, provided the original work is properly cited.

\begin{abstract}
This paper investigated chemical composition and antioxidant activities of umezu, pickling liquid of Prunus mume, from different factories in South and East China. The organic acid and phenolic acid profiles were also analyzed. Results showed that umezu was rich in organic acids and extremely sour as $P$. mume fruit in addition to its high $\mathrm{NaCl}$ level ( $\geq 20 \%)$. Total acid in umezu was more than $43.78 \mathrm{~g} / \mathrm{L}$ in which main organic acids were citric acid and malic acid. Umezu contained more than $250.54 \mathrm{mg}$ GAE/L total phenolic in which dominant phenolic acids were hydroxycinnamic acid derivatives. Umezu exhibited powerful antioxidant activities in ORAC, ABTS, DPPH, and FRAP assays. Reducing sugar, phenolic compounds, and antioxidant activities of umezu were affected by sample origins and fruit cultivars. Given its rich flavor components and high antioxidant activity, umezu could serve as a new dietary supplement or a natural preservative in food industry.
\end{abstract}

\section{Introduction}

Prunus mume, also known as Mei or green plum in China, mume or Japanese apricot in Japan, and Maesil in Korea, is a deciduous tree of the Rosaceae family [1]. The fruit of $P$. mume, weighing $12.0-30.0 \mathrm{~g}$ freshly, green in immature and yellow in mature stage as well as rich in organic acids, edible fibre, minerals, and phenolic compounds, is known to have good medicinal effects on stomach and intestine disorders [2]. Unlike many other fruits which are mainly consumed freshly, most $P$. mume fruits should be processed before consumption, due to presence of cyanoglycoside, prunasin, and amygdalin and very high organic acid content [3].

Traditionally, $P$. mume fruit was firstly pickled with salt or smoked to dry and then processed to preserved fruit or used as medicinal material [4]. For example, the pickled $P$. mume fruit (named umeboshi in Japan) has been widely used as a food garnish, sauce, juice, and liquor in China, Japan, Korea, and other Southeast Asian countries. Besides, smoked and dried immature P. mume fruit, Fructus mume (Chinese name "Wu Mei"), has been traditionally used as a medical alternative for its antitussive, expectoration, antiemetic, antidiarrheal, anthelmintic, and antipyretic actions [5]. In addition, in many other Asian countries, mainly in Japan, a few of these processed products of $P$. mume fruit, such as umeboshi and bainiku ekisu (concentrated juice of P. mume fruit), had been used as a folk remedy for fatigue, diarrhea, and fever [6].

Even though a growing number of new technologies have been developed, salt-pickling remains the dominant method for P. mume fruit processing. During pickling of $P$. mume with salt, a large amount of liquid named Meilu in China and umezu in Japan is produced. Owing to its extreme salty and sour taste, umezu is mostly disposed as sewage, causing environment pollution. Umezu, composed of salt and liquid from $P$. mume fruit, is a natural source with great potential application. To realize the industrial utilization of umezu, its nutritional values, functional properties, and potential disadvantages should be characterized. To the best of our knowledge, there are no previous reports on umezu compositional characteristics, as well as further development. In this paper, five P. mume pickling liquid (umezu) samples 
were collected from different factories in the South and East China, and their chemical constituents, including the content and proportion of organic acids and phenolic acids, and antioxidant activities were investigated.

\section{Materials and Methods}

2.1. Chemicals and Reagents. Folin-Ciocalteu phenol reagent, Trolox $^{\circledR}$ (6-hydroxy-2,5,7,8-tetramethylchroman-2-carboxylic acid), 2,4,6-tripyridyl-s-triazine (TPTZ), 2,2'-azinobis (3-ethylbenzothiazoline-6-sulfonic acid) diammonium salt (ABTS), 2,2' -azobis-(2-amidinopropane) dihydrochloride (ABAP), and $3^{\prime}, 6^{\prime}$-dihydroxyspiro[isobenzofuran- $1(3 \mathrm{H})$, $9^{\prime}$-(9H)-xanthene]-3-one disodium salt (FL) were purchased from Sigma Chemical Co. (St. Louis, MO, USA). Gallic, chlorogenic, neochlorogenic, cryptochlorogenic, caffeic, p-coumaric, protocatechuic, vanillic, and ferulic acids, catechin, and epicatechin were purchased from Biopurify Phytochemicals Ltd (Chengdu, China). HPLC-grade acetic acid and acetonitrile were obtained from Fisher (Suwanee, GA, USA). All other chemicals used were of analytical grade or above.

2.2. Umezu Samples. Two umezu samples (umezu of white mume and green mume) were acquired from Zhaoan (Fujian Province, China), while the other three samples were from Puning, Raoping, and Luhe (Guangdong Province, China), respectively, in May 2015. Both Baifen Mei and Qingzhu Mei were two dominating cultivars of $P$. mume planted in China. All umezu samples were stored in pots made of polyethylene terephthalate (PET) under $4^{\circ} \mathrm{C}$ until test.

2.3. Proximate Composition. Umezu samples were centrifuged at $3130 \times \mathrm{g}$ for $10 \mathrm{~min}$ before test. A benchtop refractometer (RFM340, Bellingham and Stanley, UK) was used to acquire soluble solids content (SSC). The $\mathrm{pH}$ value was assayed with a $\mathrm{pH}$ meter (PB -20, Sartorius, Göttingen, Germany). The $\mathrm{NaCl}$ content was determined following the Chinese National Standard (GB/T 12457-2008). TA content was determined according to AOAC method 942.15 [7]. Aliquot of $2.0 \mathrm{~mL}$ sample was diluted to $100 \mathrm{~mL}$ with ultrapure water, mixed, and then titrated with $0.1 \mathrm{M} \mathrm{NaOH}$ to an end point of $\mathrm{pH}$ 8.2. TA was calculated as \% citric acid. The total phenolic content was analyzed by the Folin-Ciocalteu (FC) colorimetric method [8]. Briefly, $0.3 \mathrm{~mL}$ neutralized umezu was mixed with $3.7 \mathrm{~mL}$ of distilled water and $2.0 \mathrm{~mL}$ of FC reagent for $6 \mathrm{~min}$. A $2.0 \mathrm{~mL}$ of $7 \%$ aqueous sodium carbonate solution was added to make up a total volume of $8.0 \mathrm{~mL}$. The mixture was incubated for $90 \mathrm{~min}$ at $25^{\circ} \mathrm{C}$. The absorbance was detected at $760 \mathrm{~nm}$ using a Shimadzu UV1800 spectrometer (Shimadzu Inc., Kyoto, Japan) using gallic acid as the standard. Total phenolic content was expressed as mg gallic acid equivalents (GAE) per $1000 \mathrm{~mL}$ sample. All the measurements were done in triplicate, and the average values were used.

2.4. Analysis of Organic Acids by HPLC. Determination of organic acid profile of umezu was conducted by high performance liquid chromatography (HPLC) as previously described [9]. An Agilent 1200 series HPLC system (Agilent Technologies, Palo Alto, California, USA) equipped with VWD detector was used to analyze organic acids. The system was run at a flow rate of $0.1 \mathrm{~mL} / \mathrm{min}$. The samples were analyzed on an Aminex HPX-87H ion exchange column $(300 \mathrm{~mm} \times 7.8 \mathrm{~mm})$ protected with a Bio-Rad guard cartridge $(30 \mathrm{~mm} \times 4.6 \mathrm{~mm})$ composed of the same stationary phase and the column (not the guard cartridge) was thermostated at $35^{\circ} \mathrm{C}$. Mobile phase was $5.0 \mathrm{mM} \mathrm{H}_{2} \mathrm{SO}_{4}$ in $\mathrm{dH}_{2} \mathrm{O}$. ChemStation Rev. A.10.02 software (Agilent Technologies) was used for data acquisition, peak integration, and standard calibration. Umezu samples were diluted with mobile phase $(1: 50)$. The injection volume was $20 \mu \mathrm{L}$. Organic acids were detected with the VWD detector at $210 \mathrm{~nm}$. Samples were quantified by comparing the retention times and peak areas with the known authentic standards. The results were expressed as $\mathrm{g} / \mathrm{L}$.

2.5. Analysis of Phenolic Compounds by HPLC. Determination of the phenolic compounds was conducted by HPLC as previously described [10]. All samples were analyzed on an Agilent 1260 HPLC system (Agilent Technologies, Palo Alto, California, USA) equipped with DAD detector and autosampler, using a $250 \times 4.6 \mathrm{~mm}, 5 \mu \mathrm{m}$ Agilent Zorbax SBC18 column (Palo Alto, CA, USA). The conditions used were as follows: column temperature $30^{\circ} \mathrm{C}$; injection volume $20 \mu \mathrm{L}$; total HPLC run time $50 \mathrm{~min}$; mobile phase $0.4 \%$ aqueous solution acetic acid (solution A); and acetonitrile (solution B). The mobile phase was programmed as follows: $0-40 \mathrm{~min}$, solution B 5-25\%; 40-45 min, solution B 25-35\%; 45-50 min, solution B $35-50 \%$. The mobile phase was pumped at a constant flow rate of $1.0 \mathrm{~mL} / \mathrm{min}$. Detection was set at $280 \mathrm{~nm}$. Before analysis, all samples were filtered through a $0.25 \mu \mathrm{m}$ membrane filter (Millipore, Billerica, MA, USA). Samples were quantified by comparing the retention times and peak areas with authentic standards. The results were expressed as $\mathrm{mg} / \mathrm{L}$.

2.6. Antioxidant Activity Determined by ORAC Assay. The oxygen radical absorbance capacity (ORAC) assay was carried out according to a modified method from our laboratory (Zhang et al., 2010). The assay was performed using black-walled 96-well plates (Corning Scientific, Corning, NY, USA). The diluted umezu was prepared with $75 \mathrm{mM}$ phosphate buffer ( $\mathrm{pH} 7.4$ ). The final reaction consisted of $20 \mu \mathrm{L}$ of umezu or $20 \mu \mathrm{L}$ of Trolox standard (range $=6.25-50 \mu \mathrm{M}$ ) and $200 \mu \mathrm{L}$ of fluorescein (final concentration $0.96 \mu \mathrm{M}$ ). The mixture was incubated at $37^{\circ} \mathrm{C}$ for $10 \mathrm{~min}$. Twenty $\mu \mathrm{L}$ of $119 \mathrm{mM}$ ABAP was then added to each well using a multichannel pipette. Fluorescence intensity was measured using a Fluoroskan Ascent FL plate-reader (Thermo Labsystems, Franklin, MA, USA) at wavelengths of $485 \mathrm{~nm}$ for excitation and $538 \mathrm{~nm}$ for emission for 35 cycles every $4.5 \mathrm{~min}$. ORAC was expressed as $\mu \mathrm{M}$ Trolox equivalents per $1000 \mathrm{~mL}$.

2.7. Antioxidant Activity Determined by ABTS Assay. The ABTS radical scavenging activity assay was carried out as previously described [11]. Briefly, ABTS was dissolved in distilled water to a concentration of $7 \mathrm{mM}$. The ABTS stock solution was then obtained by mixing $7 \mathrm{mM}$ ABTS water 
solution with $2.45 \mathrm{mM}$ potassium persulfate solution and leaving it to stand in the dark at room temperature for $12-16 \mathrm{~h}$ before use. The ABTS radical solution was diluted with methanol and adjusted to an absorbance of $0.700 \pm 0.020$ at $734 \mathrm{~nm}$. The assay was performed using 96-well microplates. $0.10 \mathrm{~mL}$ of the diluted umezu was added to $2 \mathrm{~mL}$ of the ABTS radical solution for use in each reaction. The absorbance was measured at $734 \mathrm{~nm}$. The ABTS antioxidant activity was expressed as $\mu \mathrm{g} / \mathrm{L}$ Trolox equivalents per $1000 \mathrm{~mL}$.

2.8. Antioxidant Activity Determined by FRAP Assay. The FRAP assay was carried out according to the method as previously described [12]. The working solution consisted of $25 \mathrm{~mL}$ $300 \mathrm{mM}$ acetate buffer $\left(5.1 \mathrm{~g} \mathrm{CH}_{3} \mathrm{COONa} \cdot 3 \mathrm{H}_{2} \mathrm{O}\right.$ and $20 \mathrm{~mL}$ of $\mathrm{CH}_{3} \mathrm{COOH}$ pH 3.6), $2.5 \mathrm{~mL}$ TPTZ solution (10 mM TPTZ in $40 \mathrm{mM} \mathrm{HCl}$ ), and $2.5 \mathrm{~mL} 20 \mathrm{mM} \mathrm{FeCl} \cdot 6 \mathrm{H}_{2} \mathrm{O}$ solution which was incubated $10 \mathrm{~min}$ at $37^{\circ} \mathrm{C}$ before use. A $0.2 \mathrm{~mL}$ umezu was reacted with $2.8 \mathrm{~mL}$ of the working solution for $30 \mathrm{~min}$ in the dark at room temperature. Absorbance was detected at $593 \mathrm{~nm}$ using a Shimadzu UV-1800 spectrometer. Methanol was used as the control and the standard curve was established with Trolox. The FRAP antioxidant activity was expressed as mg Trolox equivalents (TE) per $1000 \mathrm{~mL}$ umezu of sample.

2.9. Antioxidant Activity Determined by DPPH Assay. The DPPH radical scavenging capacities of umezu were performed according to a previous report [13]. Two hundred $\mu \mathrm{L}$ of six serially diluted umezu or methanol (control) samples were added to $2.8 \mathrm{~mL}$ of methanolic solution of $70 \mu \mathrm{M} \mathrm{DPPH}$. After shaking, the mixtures were placed in the dark at room temperature for $30 \mathrm{~min}$. A spectrometer (Shimadzu UV1800) was used to read their absorbance values at $515 \mathrm{~nm}$. Antioxidant activity was calculated according to the following equation in which $I \%$ stands for inhibition percentage: $I \%=$ $\left(\mathrm{Abs}_{\text {control }}-\mathrm{Abs}_{\text {sample }}\right) \times 100 / \mathrm{Abs}_{\text {control }}$. Sample concentration at which $50 \%$ DPPH scavenging effect was acquired was used to express median effective concentration (EC50) value. EC50 was calculated by constructing the percentage of DPPH scavenging versus log (phenolic concentration expressed as the volume of umezu) curves $(\mathrm{mg} / \mathrm{mL})$.

2.10. Statistical Analysis. All the analyses were performed in triplicate and results were presented as mean \pm standard deviations of each sample. Different samples were analyzed with ANOVA followed by the SNK-q test to identify differences between values. A value of $p<0.05$ was considered to be statistically different. All statistical analyses were performed using the SPSS statistical package version 13.0 (SPSS Inc., Chicago, IL, USA).

\section{Results and Discussion}

3.1. Proximate Composition. Traditional P. mume pickling process is practiced in a cubic pool as follows: one layer of fruit by one layer of salt until the pool is full; and then an inert cloth is used to cover the surface and a heavy item, usually stone, is put on the top. Salt is added at a dose of
$250-300 \mathrm{~kg}$ salt per $1000 \mathrm{~kg}$ fresh P. mume fruit. It takes more than three months for the pickling process to occur. During pickling, water and soluble substances such as sugar, organic acid, mineral, and bioactive compounds effuse from the fruits while salt is intruded into the fruits until a balance is achieved at the end. The umezu yield is $45-50 \%$ of fresh fruits.

The chemical composition could directly reflect the physiochemical property of $P$. mume umezu [4]. Table 1 summarized the proximate composition of umezu samples from five different factories in two provinces in China. As expected, most umezu samples were high in salt and acid but low in sugar. They contain $33.00-34.50^{\circ}$ Brix solid matter in which $20.36-22.01 \%$ is $\mathrm{NaCl}$. Total titratable acid content is 4.55-5.44\%, which makes them very acidic ( $\mathrm{pH} 1.85-1.90$ ). Reducing sugar content is only $5.18-8.56 \%$. The ratio of sugar to titratable acid among those samples is only 1.14-1.57. Noteworthy, the solid and $\mathrm{NaCl}$ contents of umezu from different factories were not different indicating similar pickling processing including recipe was used. Among all samples, umezu from Luhe presented the lowest total acid (4.55\%) and reducing sugar (5.18\%) while that of other four samples had similar total acid and reducing sugar contents. As reported previously, the $P$. mume fruit was an important source of phenolic antioxidant and antimicrobial agent [14-16]. The total phenolic content ranged from 250.54 to $330.74 \mathrm{mg} / \mathrm{L}$ in this study. The different phenolic content among the five umezu samples might be ascribed to different fruit cultivars and/or growing conditions as fruit quality was affected by factors including weather, environment, plant management, and so on besides species [17]. Thus, $P$. mume fruit from different species or different growing origins would render umezu samples with different chemical compositions.

3.2. Organic Acid Profile. Organic acids are important flavor regulators for acidity regulation that could confer sour flavor, control microorganism growth, prevent browning, increase solubility of metal ion, improve appetite, promote digestion, and so on [6]. The characteristic sourness of P. mume fruits is caused by the presence of free organic acids in this fruit $[9,18]$. Generally, the total titratable acid of $P$. mume fruits could be as high as $6.0-7.0 \%$ on a fresh weight basis, though its profile is diversified [2]. Organic acids, with high polarity, are hydrophilic compounds and very stable in solution [19]. Chen et al. [18] detected seven organic acids in P. mume by HPLC. Pan (2007) purified ten organic acids, including citric acid, malic acid, oxalic acid, glycolic acid, succinic acid, lactic acid, pyroglutamic acid, formic acid, acetic acid, and propionic acid from this fruit. During pickling of P. mume fruit with salt, they could easily penetrate the fruit into the pickling liquids, that is, umezu.

Typical organic acid chromatogram of umezu from different factories was presented in Figure 1 and the main organic acid contents were shown in Table 2. Seven organic acids were detected in the umezu samples, among which six organic acids were identified by HPLC. The major organic acids detected in this assay were citric acid $(67.5 \%-74.3 \%$ of total acid) and malic acid (12.9\%-18.9\% of total acid), and other minor organic acids included oxalic, succinic, lactic, and acetic acid. The organic acid profile of umezu is consistent 
TABLE 1: Proximate composition of umezu from different factories.

\begin{tabular}{lcccccc}
\hline Umezu samples & $\mathrm{pH}$ & Solid content $\left({ }^{\circ}\right.$ Brix $)$ & $\mathrm{NaCl}(\%)$ & Total acid $(\%)$ & Reducing sugar $(\%)$ & Total phenolic $(\mathrm{mg} / \mathrm{L})$ \\
\hline Fujian green mume & 1.81 & $34.03 \pm 0.04^{\mathrm{a}}$ & $22.01 \pm 0.54^{\mathrm{a}}$ & $5.44 \pm 0.24^{\mathrm{a}}$ & $8.56 \pm 0.03^{\mathrm{a}}$ & $300.77 \pm 0.37^{\mathrm{b}}$ \\
Fujian white mume & 1.90 & $33.69 \pm 0.02^{\mathrm{a}}$ & $21.22 \pm 0.15^{\mathrm{a}}$ & $5.18 \pm 0.11^{\mathrm{a}}$ & $7.05 \pm 0.05^{\mathrm{b}}$ & $250.78 \pm 0.19^{\mathrm{c}}$ \\
Luhe green mume & 1.89 & $31.43 \pm 0.11^{\mathrm{a}}$ & $20.36 \pm 0.48^{\mathrm{a}}$ & $4.55 \pm 0.15^{\mathrm{b}}$ & $5.18 \pm 0.02^{\mathrm{c}}$ & $260.47 \pm 0.85^{\mathrm{c}}$ \\
Puning green mume & 1.85 & $33.00 \pm 0.02^{\mathrm{a}}$ & $20.44 \pm 0.45^{\mathrm{a}}$ & $5.05 \pm 0.11^{\mathrm{a}}$ & $7.14 \pm 0.03^{\mathrm{b}}$ & $250.54 \pm 0.56^{\mathrm{c}}$ \\
Raoping green mume & 1.86 & $34.50 \pm 0.04^{\mathrm{a}}$ & $21.45 \pm 0.67^{\mathrm{a}}$ & $5.42 \pm 0.17^{\mathrm{a}}$ & $7.38 \pm 0.05^{\mathrm{b}}$ & $330.74 \pm 0.75^{\mathrm{a}}$ \\
\hline
\end{tabular}

Means \pm SD $(n=3)$ within each column followed by the same letter are not significantly different at the $5 \%$ level.

TABLE 2: Predominant organic acids of umezu from different factories $(\mathrm{g} / \mathrm{L})$.

\begin{tabular}{lccccccc}
\hline Umezu samples & Oxalic acid & Citric acid & Malic acid & Succinic acid & Lactic acid & Acetic acid & Total \\
\hline Fujian green mume & $0.71 \pm 0.16^{\mathrm{a}}$ & $36.93 \pm 0.34^{\mathrm{b}}$ & $7.60 \pm 0.63^{\mathrm{b}}$ & $1.01 \pm 0.19^{\mathrm{a}}$ & $4.51 \pm 0.17^{\mathrm{a}}$ & $1.30 \pm 0.02^{\mathrm{a}}$ & $52.06 \pm 1.14^{\mathrm{a}}$ \\
Fujian white mume & $0.36 \pm 0.04^{\mathrm{c}}$ & $34.06 \pm 3.54^{\mathrm{c}}$ & $9.54 \pm 1.94^{\mathrm{a}}$ & $1.13 \pm 0.04^{\mathrm{a}}$ & $4.20 \pm 0.22^{\mathrm{a}}$ & $1.15 \pm 0.08^{\mathrm{b}}$ & $50.44 \pm 5.43^{\mathrm{a}}$ \\
Luhe green mume & $0.57 \pm 0.06^{\mathrm{b}}$ & $30.89 \pm 0.73^{\mathrm{d}}$ & $6.42 \pm 0.12^{\mathrm{c}}$ & $1.26 \pm 0.24^{\mathrm{a}}$ & $3.98 \pm 0.20^{\mathrm{b}}$ & $0.66 \pm 0.21^{\mathrm{c}}$ & $43.78 \pm 0.73^{\mathrm{b}}$ \\
Puning green mume & $0.46 \pm 0.03^{\mathrm{c}}$ & $36.27 \pm 0.25^{\mathrm{b}}$ & $7.59 \pm 0.85^{\mathrm{b}}$ & $0.90 \pm 0.09^{\mathrm{b}}$ & $3.83 \pm 0.41^{\mathrm{b}}$ & $0.95 \pm 0.16^{\mathrm{b}}$ & $49.99 \pm 0.03^{\mathrm{a}}$ \\
Raoping green mume & $0.61 \pm 0.13^{\mathrm{ab}}$ & $38.13 \pm 0.76^{\mathrm{a}}$ & $6.63 \pm 0.16^{\mathrm{c}}$ & $1.21 \pm 0.21^{\mathrm{a}}$ & $3.43 \pm 0.81^{\mathrm{c}}$ & $1.34 \pm 0.06^{\mathrm{a}}$ & $51.35 \pm 1.75^{\mathrm{a}}$ \\
\hline
\end{tabular}

Means \pm SD $(n=3)$ within each column followed by the same letter are not significantly different at the $5 \%$ level.

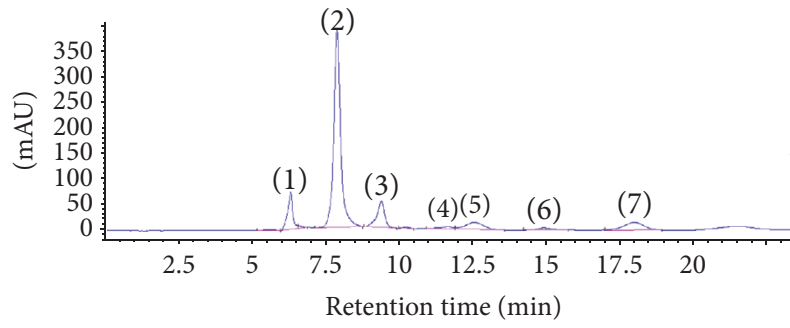

FIGURE 1: Representative chromatogram of organic acid in umezu $(\lambda$ $=210 \mathrm{~nm}$ ). (1) Oxalic acid; (2) citric acid; (3) malic acid; (4) succinic acid; (5) lactic acid; (6) acetic acid; (7) unknown.

with that of $P$. mume fruit reported by others $[2,19]$. Citric acid and malic acid are the two most abundant acids, and they account for more than $90 \%$ of total acid content in P. mume fruit [18] and more than $85 \%$ of total acid content in umezu in this study (Table 2). Noteworthily, the differences of these two major organic acids (citric acid and malic acid) among all umezu samples were significant $(p<0.05)$. Except for the different growing environment and species, the fruit maturity might also be a major influence factor [4]. As revealed by Chung et al. [4], malic acid in the fruit is higher than citric acid during the early stage, while citric acid is much more abundant than malic acid during the late maturation stage. Based on Table 2 and Figure 1, it could be concluded that umezu, enriched in organic acids, exhibited potential values in seasoning products development.

3.3. Phenolic Compound Profile. Phenolic compound is another important index for umezu exploitation. Mitani et al. [20] reported that phenolics content in fully matured P. mume flesh was as high as $1 \%$ on a dry weight basis. Phenolic acids are considered to be anti-inflammatory, anticarcinogenic,

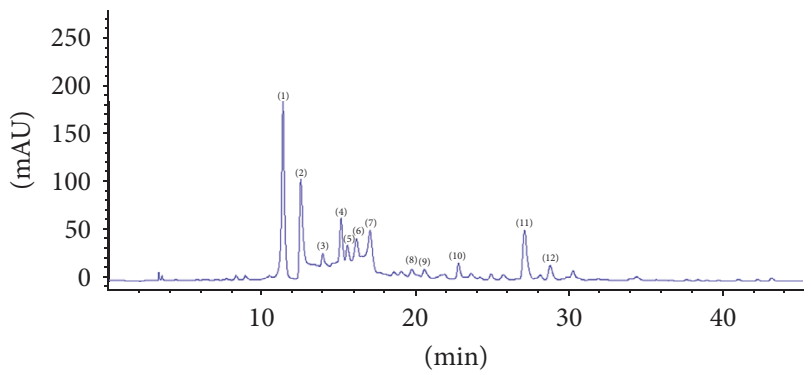

FIGURE 2: Representative chromatogram of phenolic compounds in umezu $(\lambda=280 \mathrm{~nm})$. (1) Neochlorogenic acid; (2) unknown; (3) unknown; (4) chlorogenic acid; (5) unknown; (6) unknown; (7) cryptochlorogenic acid; (8) unknown; (9) caffeic acid; (10) unknown; (11) p-coumaric acid; (12) unknown.

and antimicrobial agents, as well as antioxidants [21, 22]. Total and individual phenolic compound contents of umezu samples were shown in Tables 1 and 3 , respectively.

Phenolic composition and contents varied in umezu samples. Umezu from Raoping, Guangdong, presented the highest total phenolic content $(330.74 \mathrm{mg} / \mathrm{L})$, followed by umezu from Zhaoan, Fujian $(300.77 \mathrm{mg} / \mathrm{L})$, while the other three samples had similar total phenolic content. The individual phenolic compounds in umezu samples were assessed by HPLC/DAD and the typical phenolic chromatogram was shown in Figure 2. Five phenolic compounds were identified and quantified, namely, neochlorogenic acid, chlorogenic acid, cryptochlorogenic acid, caffeic acid, and p-coumaric acid. Neochlorogenic acid, chlorogenic acid, and cryptochlorogenic acid accounted for $58.3 \%-63.6 \%, 12.4 \%-18.1 \%$, and $15.4 \%-20.5 \%$ of total quantified phenolic compounds, respectively. In addition, caffeic acid and p-coumaric acid were very low in umezu samples. 
TABle 3: Phenolic composition of umezu of Prunus mume from different factories (mg/L).

\begin{tabular}{lccccc}
\hline Umezu samples & Neochlorogenic acid & Chlorogenic acid & Cryptochlorogenic acid & Caffeic acid & p-Coumaric acid \\
\hline Fujian green mume & $161.45 \pm 21.99^{\mathrm{a}}$ & $39.66 \pm 11.99^{\mathrm{b}}$ & $39.87 \pm 4.55^{\mathrm{b}}$ & $3.57 \pm 0.39^{\mathrm{c}}$ & $9.25 \pm 2.49^{\mathrm{b}}$ \\
Fujian white mume & $152.68 \pm 33.75^{\mathrm{b}}$ & $39.58 \pm 14.60^{\mathrm{b}}$ & $37.45 \pm 7.32^{\mathrm{b}}$ & $3.29 \pm 0.86^{\mathrm{c}}$ & $9.75 \pm 3.05^{\mathrm{b}}$ \\
Luhe green mume & $106.64 \pm 36.11^{\mathrm{c}}$ & $21.91 \pm 8.62^{\mathrm{c}}$ & $36.18 \pm 9.28^{\mathrm{b}}$ & $1.98 \pm 0.02^{\mathrm{d}}$ & $9.58 \pm 2.35^{\mathrm{b}}$ \\
Puning green mume & $147.48 \pm 14.09^{\mathrm{b}}$ & $39.08 \pm 9.18^{\mathrm{b}}$ & $37.13 \pm 4.38^{\mathrm{b}}$ & $7.04 \pm 0.88^{\mathrm{a}}$ & $9.26 \pm 2.74^{\mathrm{b}}$ \\
Raoping green mume & $163.38 \pm 48.04^{\mathrm{a}}$ & $50.79 \pm 14.21^{\mathrm{a}}$ & $45.77 \pm 12.28^{\mathrm{a}}$ & $4.77 \pm 1.36^{\mathrm{b}}$ & $15.75 \pm 3.62^{\mathrm{a}}$ \\
\hline
\end{tabular}

Means \pm SD $(n=3)$ within each column followed by the same letter are not significantly different at the $5 \%$ level.

TABLE 4: Antioxidant activities of umezu from different factories.

\begin{tabular}{lcccc}
\hline Umezu samples & ORAC $(\mu \mathrm{mol} \mathrm{TE} / \mathrm{L})$ & ABTS $(\mu \mathrm{g} / \mathrm{L})$ & FRAP $(\mu \mathrm{g} / \mathrm{L})$ & $\left.\mathrm{DPPH}^{(\mathrm{EC}} 50\right)(\mathrm{mg} / \mathrm{mL})$ \\
\hline Fujian green mume & $12298.34 \pm 145.66^{\mathrm{b}}$ & $104.67 \pm 3.05^{\mathrm{b}}$ & $176.43 \pm 3.89^{\mathrm{b}}$ & 66.00 \\
Fujian white mume & $7994.96 \pm 266.62^{\mathrm{d}}$ & $94.52 \pm 10.25^{\mathrm{c}}$ & $162.09 \pm 9.16^{\mathrm{d}}$ & 43.67 \\
Luhe green mume & $10361.99 \pm 173.19^{\mathrm{c}}$ & $24.96 \pm 62.72^{\mathrm{d}}$ & $172.95 \pm 2.44^{\mathrm{c}}$ & 56.83 \\
Puning green mume & $7741.43 \pm 99.94^{\mathrm{d}}$ & $94.96 \pm 25.21^{\mathrm{c}}$ & $162.09 \pm 4.24^{\mathrm{d}}$ & 65.96 \\
Raoping green mume & $17433.72 \pm 145.66^{\mathrm{a}}$ & $195.83 \pm 26.44^{\mathrm{a}}$ & $186.43 \pm 3.39^{\mathrm{a}}$ & 81.70 \\
\hline
\end{tabular}

Means \pm SD $(n=3)$ within each column followed by the same letter are not significantly different at the $5 \%$ level.

Mitani et al. [20] identified 5-O-caffeoylquinic acid (neochlorogenic acid) and 3-O-caffeoylquinic acid (chlorogenic acid) from the P. mume flesh, indicating that the majority of phenolics in $P$. mume fruit were hydroxycinnamic acid derivatives. Xia et al. [23] identified three chlorogenic acid isomers, namely, 3-O-caffeoylquinic acid, 5-O-caffeoylquinic acid, and 4-O-caffeoylquinic acid (cryptochlorogenic acid), from $P$. mume seeds and found 3-O-caffeoylquinic acid was of the highest level in these three isomers. In this study, we also detected the chlorogenic acid isomers in $P$. mume seeds but did not find them (data not shown). According to literatures and our analysis, it is likely that chlorogenic acid isomers in umezu were from P. mume flesh, not seeds. During pickling, phenolic compounds in $P$. mume flesh could permeate into umezu. Chlorogenic acid isomers are stable under acidic $\mathrm{pH}$; therefore, they kept a high concentration after pickling was finished. Low level of caffeic acid and p-coumaric acid in umezu might be hydrolysate of chlorogenic acid isomers. Narita and Inouye [15] reported that chlorogenic acid could hydrolyze into phenolic acids, such as caffeic acid, cis/transp-coumaric acid, and ferulic acid.

3.4. Antioxidant Activities. P. mume fruits contain multiple antioxidants, including organic acids, isoflavones, and phenolic acids [24]. Antioxidant activities of umezu samples were compared in terms of ORAC, $\mathrm{ABTS}^{+}$, FRAP, and $\mathrm{DPPH}^{\circ}$ scavenging capacity (Table 4 ).

Umezu obtained from Fujian white mume and Puning green mume had similar antioxidant properties in terms of ORAC and $\mathrm{ABTS}^{+}$scavenging as well as FRAP. In all antioxidant activity assays, umezu acquired from Raoping green mume and Fujian green mume, however, exhibited significantly higher radical scavenging capacity and reducing power than other samples. Particularly, umezu that came from Raoping green mume presented almost twofold antioxidant capacity compared with those from Fujian white mume and Puning green mume in ABTS and ORAC values. This could be explained by their higher level of antioxidant ingredients, of which total phenolic acids $(330.74 \mathrm{mg} / \mathrm{L})$ and organic acids $(51.53 \mathrm{~g} / \mathrm{L})$ ranked almost first among all umezu samples (Tables 1 and 2). Reflecting such wealth of organic acids and phenolic acids, the reducing power reflected by FRAP value for umezu samples showed high values, ranging from $162.9 \mu \mathrm{g} / \mathrm{L}$ to $186.43 \mu \mathrm{g} / \mathrm{L}$ Trolox equivalent, depending upon the species and origin areas. In accordance with our results, Debnath et al. [24] revealed that the extract of Mume Fructus exhibited high scavenging activities on DPPH, ABTS, hydroxyl, and superoxide radicals with the $\mathrm{IC}_{50}$ of $0.40,0.36$, 1.75 , and $1.60 \mathrm{mg} / \mathrm{ml}$, respectively. It was reported that the reducing power properties are generally associated with the presence of reductones, which have been shown to exert an antioxidant action by breaking the free radical chains by donating a hydrogen atom [25].

Noteworthily, in all antioxidant activity assays, only ORAC and FRAP of the umezu followed the same trends as their phenolic acids contents; $\mathrm{ABTS}^{+}$and $\mathrm{DPPH}^{*}$ scavenging capacity went different. Luhe green mume and Raoping green mume presented the lowest and strongest scavenging activities of $\mathrm{ABTS}^{+}$, with which ABTS values being $24.96 \mu \mathrm{g} / \mathrm{L}$ and $195.83 \mu \mathrm{g} / \mathrm{L}$, respectively. The $\mathrm{DPPH}^{\circ}$ scavenging capacity of samples exhibited the descending order: Raoping green mume $>$ Fujian green mume $>$ Puning green mume $>$ Luhe green mume $>$ Fujian white mume. Umezu samples obtained from Fujian green mume and Puning green mume displayed almost equivalent scavenging activity on $\mathrm{DPPH}^{\circ}$ radical $(p>0.05)$. The $\mathrm{DPPH}^{*}$ scavenging ability of umezu samples obtained from Fujian white mume and Luhe green mume was much lower than other samples, but their EC50 values were still higher than $40 \mathrm{mg} / \mathrm{ml}$, which may represent its medicinal value [26]. 


\section{Conclusions}

Chemical composition and antioxidant activities of umezu from five $P$. mume pickling factories in China were investigated. These samples contained $33.00-34.50^{\circ}$ Brix solid matter in which $\mathrm{NaCl}$ was $20.36-22.01 \%$. Total titratable acid content was $4.55-5.44 \%$ which makes it with very low $\mathrm{pH}$ (1.85-1.90), while reducing sugar content was only $5.18-8.56 \%$. Umezu was high in organic acids $(>43 \mathrm{~g} / \mathrm{L})$ in which six organic acids were identified and the dominant ones were citric acid and malic acid. It also contained abundant phenolic compounds ( $>250 \mathrm{mg} / \mathrm{L}$ ) in which the predominant phenolic acids were neochlorogenic acid, chlorogenic acid, and cryptochlorogenic acid. Umezu obtained from different factories also exhibited strong radical scavenging activities and ferrous reduction ability. Total phenolics were partially responsible for the antioxidant activity assessed by ORAC, ABTS, DPPH, and FRAP assays. Considering the results obtained, it might be anticipated that the umezu could be used as sauce or a natural preservative in food and/or pharmaceutical industry with suitable desalting technology.

\section{Conflicts of Interest}

The authors declare that they have no conflicts of interest.

\section{Acknowledgments}

This work was supported by Guangdong Province Science and Technology Program (Grant nos. 2013B090600093, 2014B040404059, and 2015A040404031). Thanks are due to Dr. Jianping Wu for providing language help.

\section{References}

[1] R. Tzonev and M. Yamaguchi, "Investigations on some FarEast Prunus species: Phenology," in International Symposium on Apricot Culture, I. Karayiannis, Ed., vol. 1 and 2, pp. 239-242, 1999.

[2] M. Miyazawa, T. Yamada, and H. Utsunomiya, "Suppressive effect of the Sos-inducing activity of chemical mutagen by citric acid esters from Prunus mume Sieb. Et Zucc. using the Salmonella typhimurium Ta1535/Psk1002 Umu Test," Natural Product Research (Formerly Natural Product Letters), vol. 17, no. 5, pp. 319-323, 2003.

[3] I. F. Bolarinwa, C. Orfila, and M. R. A. Morgan, "Amygdalin content of seeds, kernels and food products commerciallyavailable in the UK," Food Chemistry, vol. 152, pp. 133-139, 2014.

[4] H.-S. Chung, D.-S. Kim, H.-S. Kim, Y.-G. Lee, and J.-H. Seong, "Effect of freezing pretreatment on the quality of juice extracted from Prunus mume fruit by osmosis with sucrose," LWT-Food Science and Technology, vol. 54, no. 1, pp. 30-34, 2013.

[5] X.-T. Yan, W. Li, Y.-N. Sun et al., "Identification and biological evaluation of flavonoids from the fruits of Prunus mume," Bioorganic \& Medicinal Chemistry Letters, vol. 24, no. 5, pp. 1397-1402, 2014.

[6] N. Shirasaka, R. Takasaki, and H. Yoshizumi, "Changes in lyoniresinol content and antioxidative activity of pickled Ume during the seasoning process," Journal of the Japanese Society for
Food Science and Technology-Nippon Shokuhin Kagaku Kogaku Kaishi, vol. 52, no. 10, pp. 495-498, 2005.

[7] AOAC, Official Methods of Analysis of AOAC International, AOAC International, 17th edition, 2002.

[8] V. Dewanto, W. Xianzhong, K. K. Adom, and R. H. Liu, "Thermal processing enhances the nutritional value of tomatoes by increasing total antioxidant activity," Journal of Agricultural and Food Chemistry, vol. 50, no. 10, pp. 3010-3014, 2002.

[9] H. A. Eyéghé-Bickong, E. O. Alexandersson, L. M. Gouws, P. R. Young, and M. A. Vivier, "Optimisation of an HPLC method for the simultaneous quantification of the major sugars and organic acids in grapevine berries," Journal of Chromatography B-Analytical Technologies in the Biomedical and Life Sciences, vol. 885-886, pp. 43-49, 2012.

[10] H. Ti, Q. Li, R. Zhang et al., "Free and bound phenolic profiles and antioxidant activity of milled fractions of different indica rice varieties cultivated in southern China," Food Chemistry, vol. 159, pp. 166-174, 2014.

[11] N. J. Miller and C. A. Rice-Evans, "Factors influencing the antioxidant activity determined by the $\mathrm{ABTS}^{\circ+}$ radical cation assay," Free Radical Research, vol. 26, no. 3, pp. 195-199, 1997.

[12] F. Biglari, A. F. M. AlKarkhi, and A. M. Easa, "Antioxidant activity and phenolic content of various date palm (Phoenix dactylifera) fruits from Iran," Food Chemistry, vol. 107, no. 4, pp. 1636-1641, 2008.

[13] R. F. Zhang, F. X. Zhang, M. W. Zhang et al., "Phenolic composition and antioxidant activity in seed coats of 60 chinese black soybean (Glycine max L. Merr.) varieties," Journal of Agricultural and Food Chemistry, vol. 59, no. 11, pp. 5935-5944, 2011.

[14] S.-C. Jo, K.-C. Nam, B.-R. Min et al., "Antioxidant activity of Prunus mume extract in cooked chicken breast meat," International Journal of Food Science and Technology, vol. 41, pp. 15-19, 2006.

[15] Y. Narita and K. Inouye, "Degradation kinetics of chlorogenic acid at various $\mathrm{pH}$ values and effects of ascorbic acid and epigallocatechin gallate on its stability under alkaline conditions," Journal of Agricultural and Food Chemistry, vol. 61, no. 4, pp. 966-972, 2013.

[16] T. Otsuka, T. Tsukamoto, H. Tanaka et al., "Suppressive effects of fruit-juice concentrate of prunus mume sieb. et zucc. (Japanese apricot, Ume) on helicobacter pyloriinduced glandular stomach lesions in Mongolian gerbils," Asian Pacific Journal of Cancer Prevention, vol. 6, no. 3, pp. 337-341, 2005.

[17] E. J. Shin, H. J. Hur, M. J. Sung et al., "Ethanol extract of the Prunus mume fruits stimulates glucose uptake by regulating PPAR- $\gamma$ in $\mathrm{C}_{2} \mathrm{C}_{12}$ myotubes and ameliorates glucose intolerance and fat accumulation in mice fed a high-fat diet," Food Chemistry, vol. 141, no. 4, pp. 4115-4121, 2013.

[18] Z.-G. Chen, B.-T. En, and Z.-Q. Zhang, "Simultaneous determination of eight organic acids in Fructus mume by RP-HPLC," Zhongguo Zhong yao za zhi = Zhongguo zhongyao zazhi = China journal of Chinese Materia Medica, vol. 31, no. 21, pp. 1783-1786, 2006.

[19] Y. Yu, G. Xiao, Y. Xu, J. Wu, Y. Zhang, and W. Chen, "Changes of quality in the fruits of Prunus mume during deacidification by fermentation with Lactobacillus fermentium," Journal of Food Science, vol. 80, no. 2, pp. M405-M410, 2015.

[20] T. Mitani, A. Horinishi, K. Kishida et al., "Phenolics profile of mume, Japanese apricot (Prunus mume Sieb. et Zucc.) fruit," Bioscience, Biotechnology, and Biochemistry, vol. 77, no. 8, pp. 1623-1627, 2013. 
[21] Y. Konishi, S. Kobayashi, and M. Shimizu, "Transepithelial transport of p-coumaric acid and gallic acid in Caco-2 cell monolayers," Bioscience, Biotechnology, and Biochemistry, vol. 67, no. 11, pp. 2317-2324, 2003.

[22] S. Kamiloglu, C. Grootaert, E. Capanoglu et al., "Antiinflammatory potential of black carrot (Daucus carota L.) polyphenols in a co-culture model of intestinal Caco-2 and endothelial EA.hy926 cells," Molecular Nutrition \& Food Research, vol. 61, no. 2, Article ID 1600455, pp. 1-11, 2017.

[23] D. Xia, X. Wu, J. Shi, Q. Yang, and Y. Zhang, "Phenolic compounds from the edible seeds extract of Chinese Mei (Prunus mume Sieb. et Zucc) and their antimicrobial activity," LWT- Food Science and Technology, vol. 44, no. 1, pp. 347-349, 2011.

[24] T. Debnath, J. P. Bak, N. B. Samad, H. L. Jin, B. R. Lee, and B. O. Lim, "Antioxidant activity of mume fructus extract," Journal of Food Biochemistry, vol. 36, no. 2, pp. 224-232, 2012.

[25] N. Sayari, A. Sila, R. Balti et al., "Antioxidant and antibacterial properties of Citrus paradisi barks extracts during turkey sausage formulation and storage," Biocatalysis and Agricultural Biotechnology, vol. 4, no. 4, pp. 616-623, 2015.

[26] C. J. Seneviratne, R. W. K. Wong, U. Hägg et al., "Prunus mume extract exhibits antimicrobial activity against pathogenic oral bacteria," International Journal of Paediatric Dentistry, vol. 21, no. 4, pp. 299-305, 2011. 

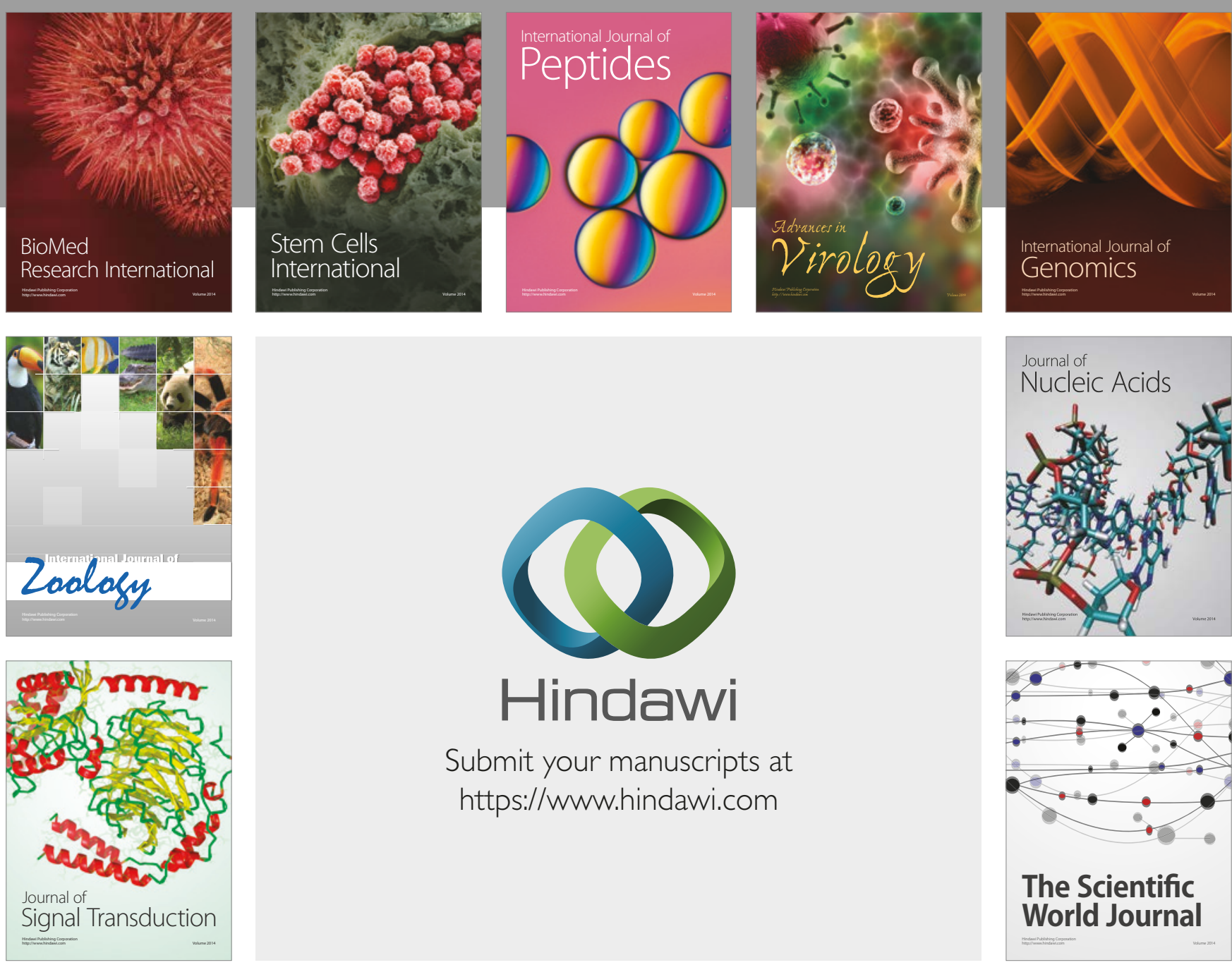

Submit your manuscripts at

https://www.hindawi.com
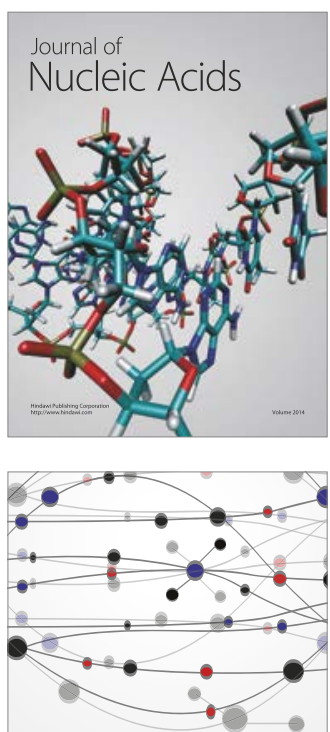

The Scientific World Journal

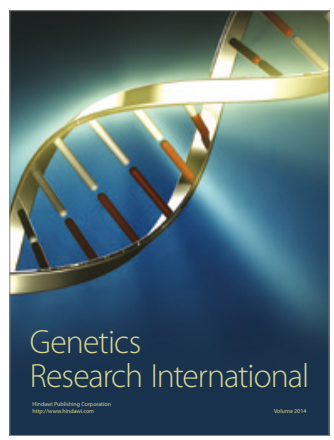

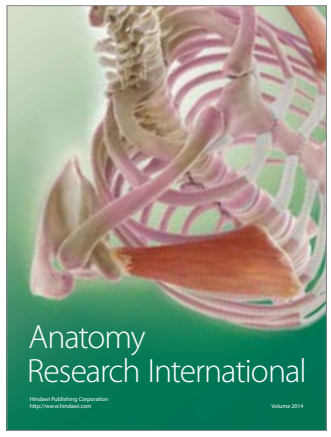

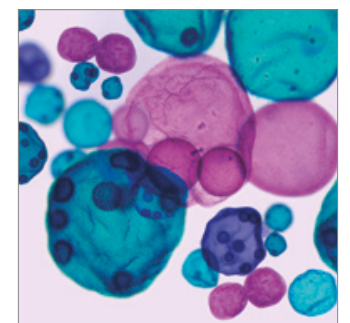

International Journal of Microbiology
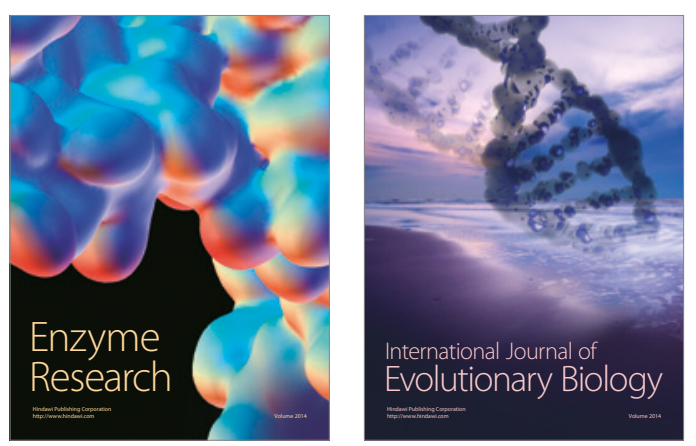
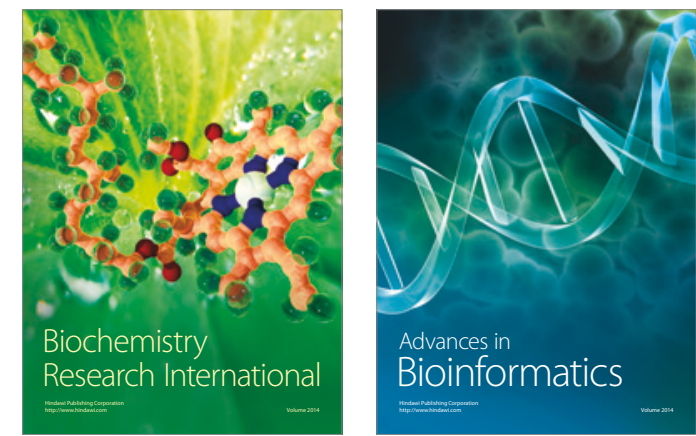

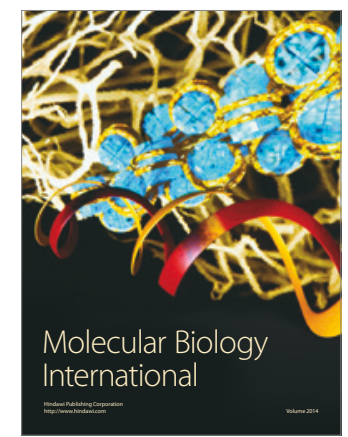

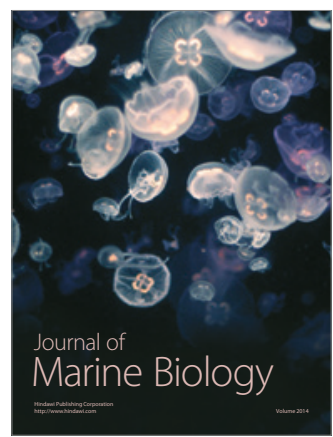

